\title{
Notes on the Nazeris fauna of Yunnan Province, China (Coleoptera, Staphylinidae, Paederinae)
}

\author{
Jia-Yao Hu ${ }^{1,2, \dagger}$, Li-Zhen Li ${ }^{2, \ddagger}$, Yun-long Zhao ${ }^{1, \S}$ \\ I Department of Biology, East China Normal University, 3663 North Zhongshan Road, Shanghai, 200062 \\ P. R. China 2 Department of Biology, Shanghai Normal University, 100 Guilin Road, Shanghai, 200234 P. \\ R. China \\ † urn:lsid:zoobank.org:author:7DDE2164-18DE-4D55-A5AB-FEB0F9388A38 \\ † urn:lsid:zoobank.org:author:BBACC7AE-9B70-4536-ABBE-54183D2ABD45 \\ § urn:lsid:zoobank.org:author:ED604F1A-C78B-4AAC-916C-A73ABOA2EC7D \\ Corresponding author: Yun-long Zhao (ylzhao@bio.ecnu.edu.cn)
}

Academic editor: Volker Assing | Received 9 March 2010 | Accepted 12 January 2011 | Published 1 March 2011

urn:lsid:zoobank.org:pub:E27D8AB1-223C-4246-B208-400014DDDF7E

Citation: Hu J-Y, Li L-Z, Zhao Y-L (2011) Notes on the Nazeris fauna of Yunnan Province, China (Coleoptera, Staphylinidae, Paederinae). ZooKeys 84: 13-21. doi: 10.3897/zookeys.84.1189

\begin{abstract}
Two new species of the genus Nazeris Fauvel collected from Nabanhe Nature Reserve, Yunnan Province, are described under the names of $N$. nabanhensis sp. n. and N. caoi sp. n. The male sexual characters are described and illustrated. A key to the Nazeris species of Yunnan is provided. A map of the collecting sites is given.
\end{abstract}

\section{Keywords}

Coleoptera, Staphylinidae, Paederinae, Nazeris, key, Yunnan, China, new species

\section{Introduction}

The genus Nazeris Fauvel (1873: 298) can be readily distinguished from other Paederinae by the labrum having four teeth at the front margin and the bi-lobed 4th tarsal segments. Up to the present, 51 species and subspecies of Nazeris have been recorded from China. Yunnan is a mountainous province located in Southwest China, from 
which nine species of Nazeris have been described: N. zhangi Watanabe \& Xiao (1993: 130) from "Yu'an-shan near Kunming City", N. giganteus Watanabe \& Xiao (1997:2) and $N$. daliensis Watanabe \& Xiao (1997: 7) from "Diancang shan Mts., Dali shi", $N$. alpinus Watanabe \& Xiao (1997: 5) from "Mt. Yulongxue shan, Lijiang County", $N$. jizushanensis Watanabe \& Xiao (1997: 9) from "Mt. Jizu Shan, Binchuan County", $N$. baibuaensis Watanabe \& Xiao (2000: 312), N. ishiianus Watanabe \& Xiao (2000: 319) and N. nomurai Watanabe \& Xiao (2000: 316) from "Gaoligong Shan Mts., Baoshan area", $N$. huanxipoensis Watanabe \& Xiao (2000: 318) from "Huanxipo, Tengchong Xian". Only two species have become known from the three countries adjacent to Yunnan (Myanmar, Laos and Vietnam): Nazeris coomani Jarrige (1948: 40) (redescribed by Rougemont 1988: 775) from "du mont Bavi, Tonkin" (Vietnam) and Nazeris odzisan Watanabe (1996: 1) from "Mt. Tam Dao, Vinh Phu Prov." (Vietnam).

The specimens from Yunnan Province contained another two undescribed species, $N$. nabanhensis sp. n. and $N$. caoi sp. n. The male sexual characters of the two new species are described and illustrated. A map (fig. 13) of the collecting sites of Nazeris species in Yunnan and a key to the Yunnan species are provided.

The types are deposited in the Insect Collections of Department of Biology, Shanghai Normal University, Shanghai, P. R. China (SHNUC).

\section{Methods}

The specimens were collected from decaying leaf litter of forest floors by hand sifting. They were killed with ethyl acetate and dried. To examine the male genitalia, the last four abdominal segments were detached from the body after softening in hot water. The aedeagi and sternites were mounted in Euparal on plastic slides. Drawings were made using an Olympus SZ61 microscope. Photos were taken with an Olympus E420 camera mounted on an Olympus SZX12 stereoscope. Material of other Yunnanese Nazeris species was not examined. The characters used in comparative remarks and keys are according to descriptions of Watanabe and Xiao (1993, 1997, 2000), Watanabe (1996), Jarrige (1948) and Rougemont (1988).

\section{Measurements}

Body length: measured from anterior margin of labrum to end of abdomen;

Forebody length: measured from anterior margin of labrum to elytral apices;

Eye length: longitudinal length of eye in dorsal view;

Postocular length: length of postocular portion in dorsal view;

Head width: width of head across eyes;

Pronotum width: width of pronotum across the widest part;

Elytra width: width of elytra across the widest part;

Head length: measured from front margin of head to its posterior margin; 
Pronotum length: measured from front margin of pronotum to its posterior margin; Elytra length: measured from humeral angle to apicolateral angle.

\section{Descriptions}

\section{Nazeris nabanbensis sp. $\mathrm{n}$.}

urn:lsid:zoobank.org:act:7B0F8A68-2EEE-412E-9090-9F1CE8EBA8ED

Figs 1, 3-7

Type material. CHINA: Holotype: Yunnan Prov.: male, Jinghong City, Nabanhe Nature Reserve, Benggangxinzhai, 1,750m, 16. XI. 2008, Hu Jia-Yao \& Tang Liang leg. Paratypes: 2 females, Jinghong City, Nabanhe Nature Reserve, Bengganghani, Nanmugahe, 1,700m, 11. XI. 2008, Hu Jia-Yao \& Tang Liang leg.; 1 female, Jinghong City, Nabanhe Nature Reserve, Bengganghani, 1,800m, 14. XI. 2008, Hu Jia-Yao \& Tang Liang leg.; 5 males, 8 females, same locality as holotype, 3. V. 2009, Hu Jia-Yao \& Yin Zi-Wei leg.; 1 female, Jinghong City, Nabanhe Nature Reserve, Bengganghani, Nanmugahe, 1,700m, 27. IV. 2009, Hu Jia-Yao \& Yin Zi-Wei leg.; 3 females, Jinghong City, Nabanhe Nature Reserve, Bengganghani, Chuguohe, 1,700m, 28. IV. 2009, Hu Jia-Yao \& Yin Zi-Wei leg.; 1 male, 1 female, Jinghong City, Nabanhe Nature Reserve, Bengganghani, 1,650m, 29. IV. 2009, Hu Jia-Yao \& Yin Zi-Wei leg.; 1 male, Jinghong City, Nabanhe Nature Reserve, Bengganghani, Nanmugahe, 1700m, 30. IV. 2009, Hu Jia-Yao \& Yin Zi-Wei leg.; 4 females, Jinghong City, Nabanhe Nature Reserve, Bengganghani, 1,650m, 30. IV. 2009, Hu Jia-Yao \& Yin Zi-Wei leg. SHNUC.

Description. Body length: $5.8-6.4 \mathrm{~mm}$; forebody length: $3.3-3.5 \mathrm{~mm}$.

Male. Body (Fig. 1) elongate, dark brown, with labrum, coxae, and basal antennomeres reddish yellow, the remaining antennomeres, maxillary palpi and legs yellow, with exception for coxae.

Head suborbicular, longer than wide (length/width $=1.18$ ); postocular portion 1.96 times as long as eye length; punctation coarse, dense, and umbilicate; interstices reduced to narrow ridges. Antennae slender; relative length of each segment from 1 to $11: 42.0: 15.0: 29.0: 23.0: 22.5: 22.0: 19.0: 17.0: 15.5: 14.0: 20.0$; relative width of each segment from 1 to $11: 12.0: 7.5: 6.0: 6.0: 6.0: 6.0: 6.0: 6.0: 6.0: 7.5: 7.5$.

Pronotum convex, oval, longer than wide (length/width $=1.20$ ), narrower (pronotum $/$ head $=0.93$ ) and shorter (pronotum/head $=0.94$ ) than head; prosternum with strong longitudinal median carina, which disappears behind anterior margin. Elytra shorter than wide $($ length/width $=0.91)$, distinctly shorter $($ elytra/pronotum $=0.74)$ and slightly narrower (elytra/pronotum $=0.97$ ) than pronotum.

Abdomen elongate, tergites without any microsculpture. Seventh sternite (Fig. 3) trapezoidally emarginated in middle of posterior margin and distinctly depressed in front of emargination; 8th sternite (Fig. 4) V-shaped deeply excised in middle of posterior margin. Aedeagus (Figs 5, 6 and 7) well sclerotized; apical part of me- 

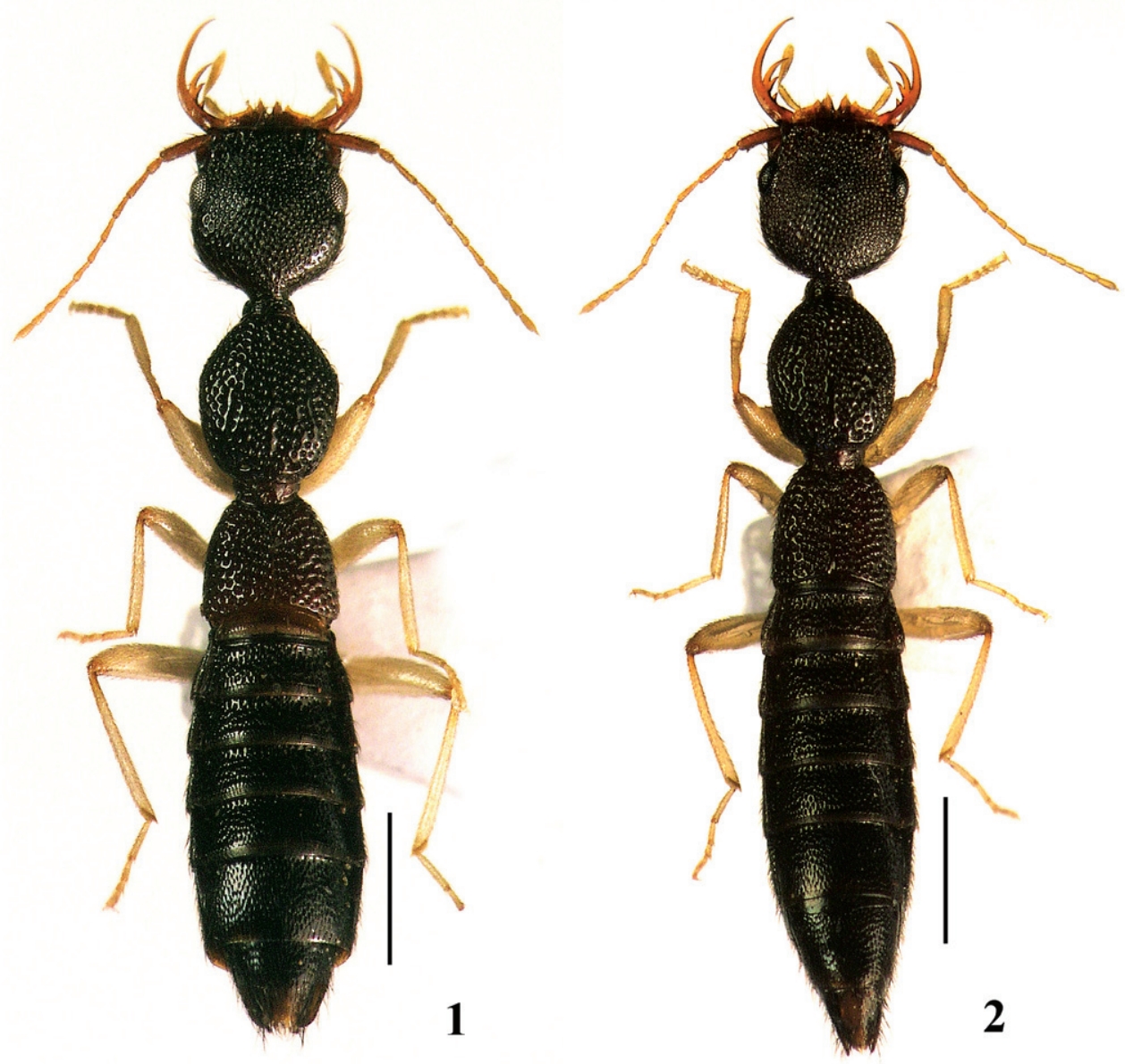

Figures I-2. Habitus of Nazeris. I N. nabanhensis sp. n. 2 N. caoi sp. n. Scale bars $1 \mathrm{~mm}$.

dian lobe in dorsal view tri-lobed, median part cone-shaped, two outer parts acute at apices, with little agnail in each outer side near apex; dorso-lateral apophyses slightly curved inward, distinctly widened near apex, extending beyond apices of median lobe.

Female. Seventh and 8th sternites simple. The other characters are similar to those of male.

Remarks. The new species is similar to $N$. daliensis Watanabe (1997: 7) from Yunnan Province in appearance, but it can be distinguished from the latter by the following characters: elytra slightly narrower than pronotum (in $N$. daliensis nearly as wide as, or slightly broader than pronotum); depth of excision of male 8th sternite nearly half of middle length of sternite (in $N$. daliensis much shallower, nearly $1 / 3$ of middle length of 8 th sternite); apical part of median lobe of aedeagus in dorsal view tri-lobed (in $N$. daliensis not lobed). The new species can be distinguished from $N$. coomani Jarrige (1948: 40) from Vietnam by head with umbilicate punctation (in $N$. 

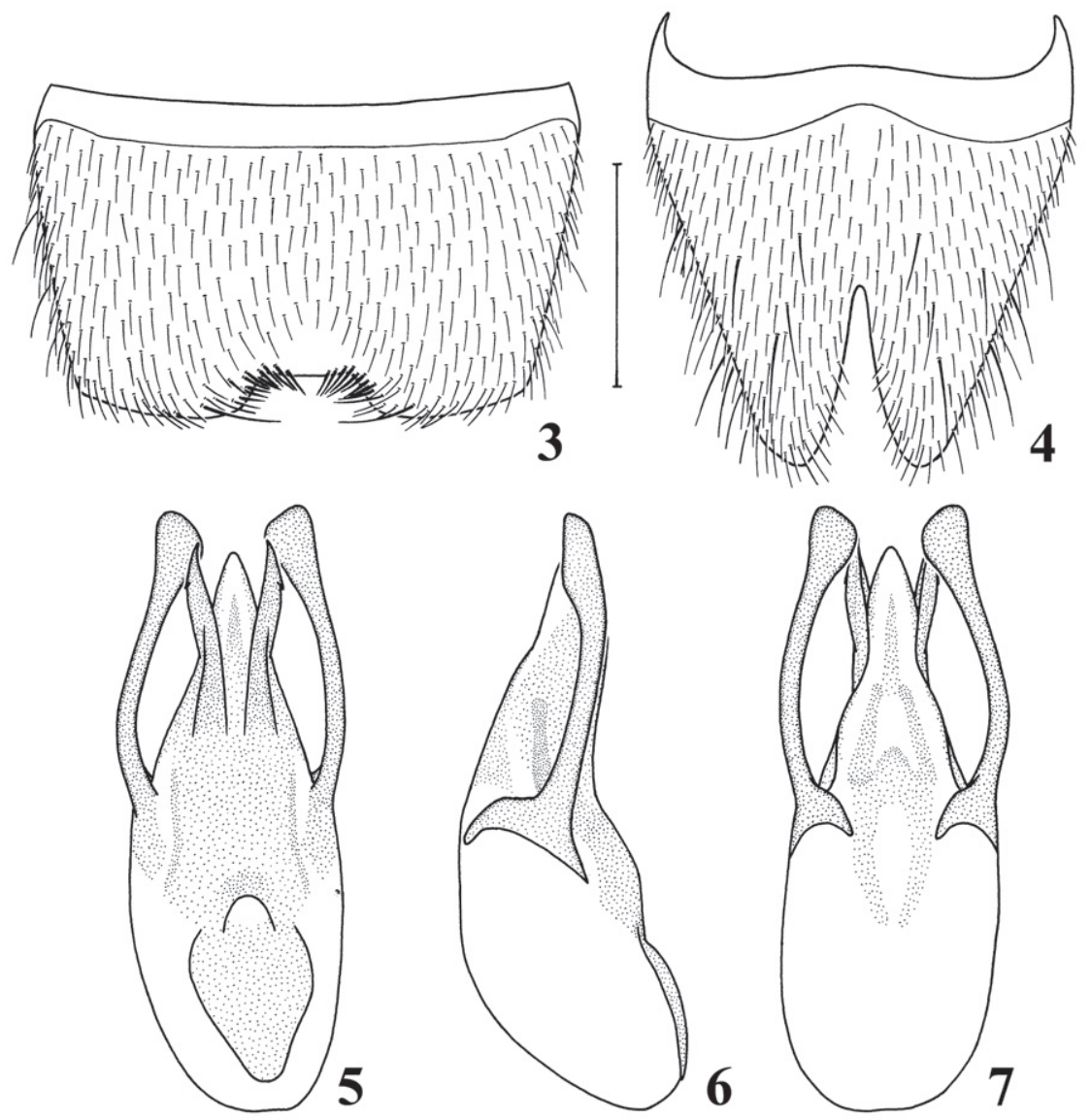

Figures 3-7. Details of Nazeris nabanhensis sp. n. $\mathbf{3}$ male 7th sternite $\mathbf{4}$ male 8 th sternite $\mathbf{5}$ aedeagus, in dorsal view $\mathbf{6}$ aedeagus, in lateral view $\mathbf{7}$ aedeagus, in ventral view. Scale bar: $0.5 \mathrm{~mm}$.

coomani punctation of head simple) and distinguished from N. odzisan Watanabe (1996: 1) from Vietnam by elytra shorter than wide (in N. odzisan elytra longer than wide); dorso-lateral apophyses of aedeagus extending beyond apices of median lobe (in N. odzisan not extending to apices of median lobe).

Etymology. The specific name is derived from the name of the type locality: $\mathrm{Na}-$ banhe Nature Reserve.

\section{Nazeris caoi sp. $\mathbf{n}$.}

urn:Isid:zoobank.org:act:3B251645-1B6B-4388-ACEC-4E5B42C4A858

Figs 2, 8-12

Type material. CHINA: Holotype: Yunnan Prov.: male, Jinghong City, Nabanhe Nature Reserve, Bengganghani, 1,930m, 14. XI. 2008, Hu Jia-Yao \& Tang Liang leg. 

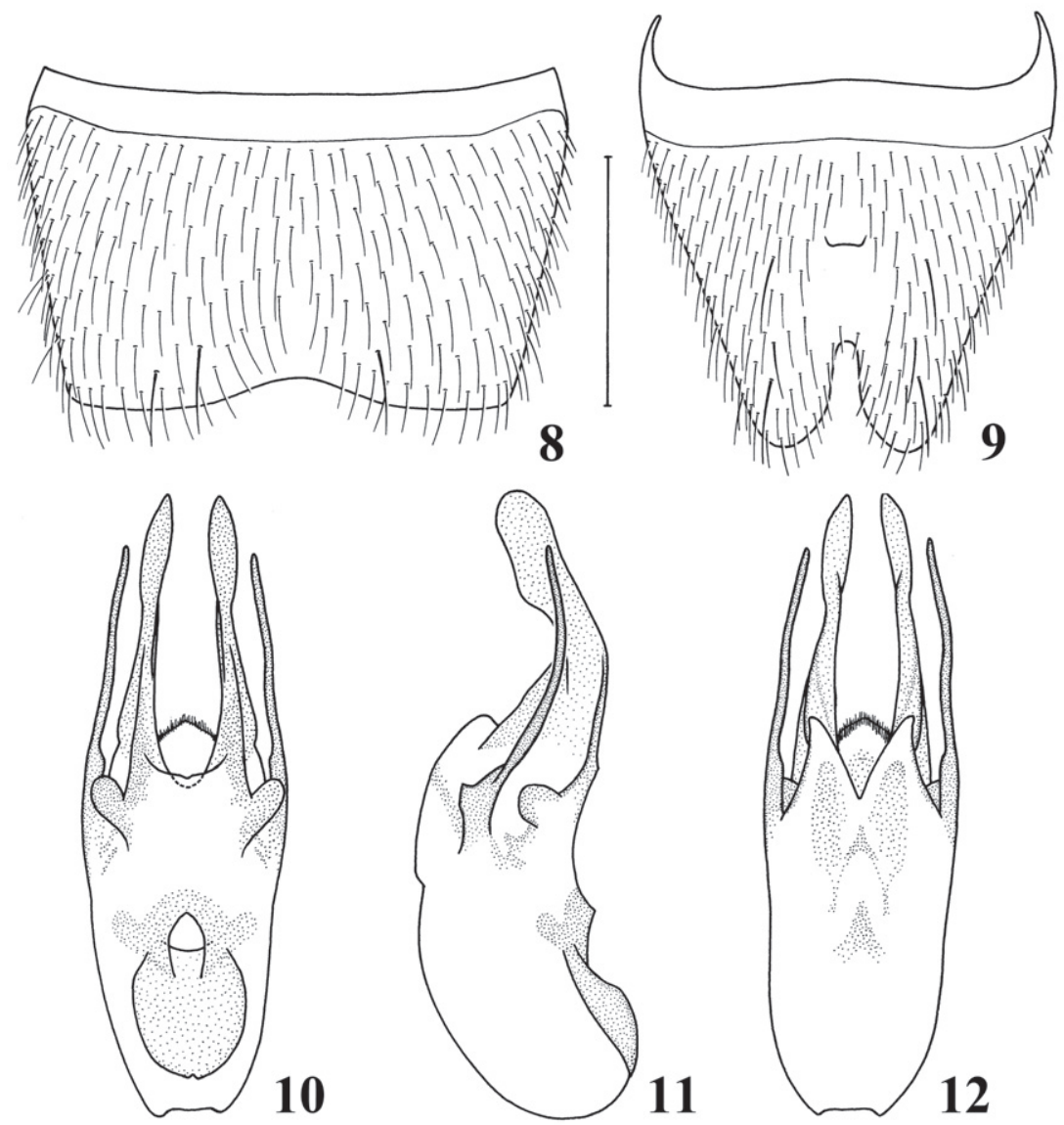

Figures 8-1 2. Details of Nazeris caoi sp. n. 8 male 7 th sternite $\mathbf{9}$ male 8th sternite $\mathbf{I} \mathbf{0}$ aedeagus, in dorsal view $\mathbf{I} \mathbf{I}$ aedeagus, in lateral view $\mathbf{I} \mathbf{2}$ aedeagus, in ventral view. Scale bar: $0.5 \mathrm{~mm}$.

Paratypes 1 male, same data as holotype; 1 female, Jinghong City, Nabanhe Nature Reserve, Bengganghani, 1,900m, 1. V. 2009, Hu Jia-Yao \& Yin Zi-Wei leg. SHNUC.

Description. Body length: 6.1-6.4 mm; forebody length: 3.3-3.6 mm.

Male. Body (Fig. 2) elongate, dark brown, with labrum, coxae, and basal two antennomeres reddish yellow, the remaining antennomeres, maxillary palpi and legs yellow, with exception for coxae.

Head suborbicular, slightly longer than wide (length/width = 1.07); postocular portion 2.14 times as long as eye length; punctation coarse, dense, and umbilicate; interstices reduced to narrow ridges. Antennae slender; relative length of each segment from 1 to $11: 42.0: 13.5: 30.0: 23.0: 21.0: 21.0: 19.0: 18.0: 18.0: 16.0: 22.0$; relative width of each segment from 1 to $11: 10.5: 7.0: 6.5: 6.0: 5.5: 6.0: 5.5: 5.5$ : $6.0: 6.5: 7.0$.

Pronotum convex, oval, longer than wide (length/width $=1.19$ ), narrower (pronotum $/$ head $=0.88)$ and shorter $($ pronotum $/$ head $=0.98)$ than head; prosternum with 


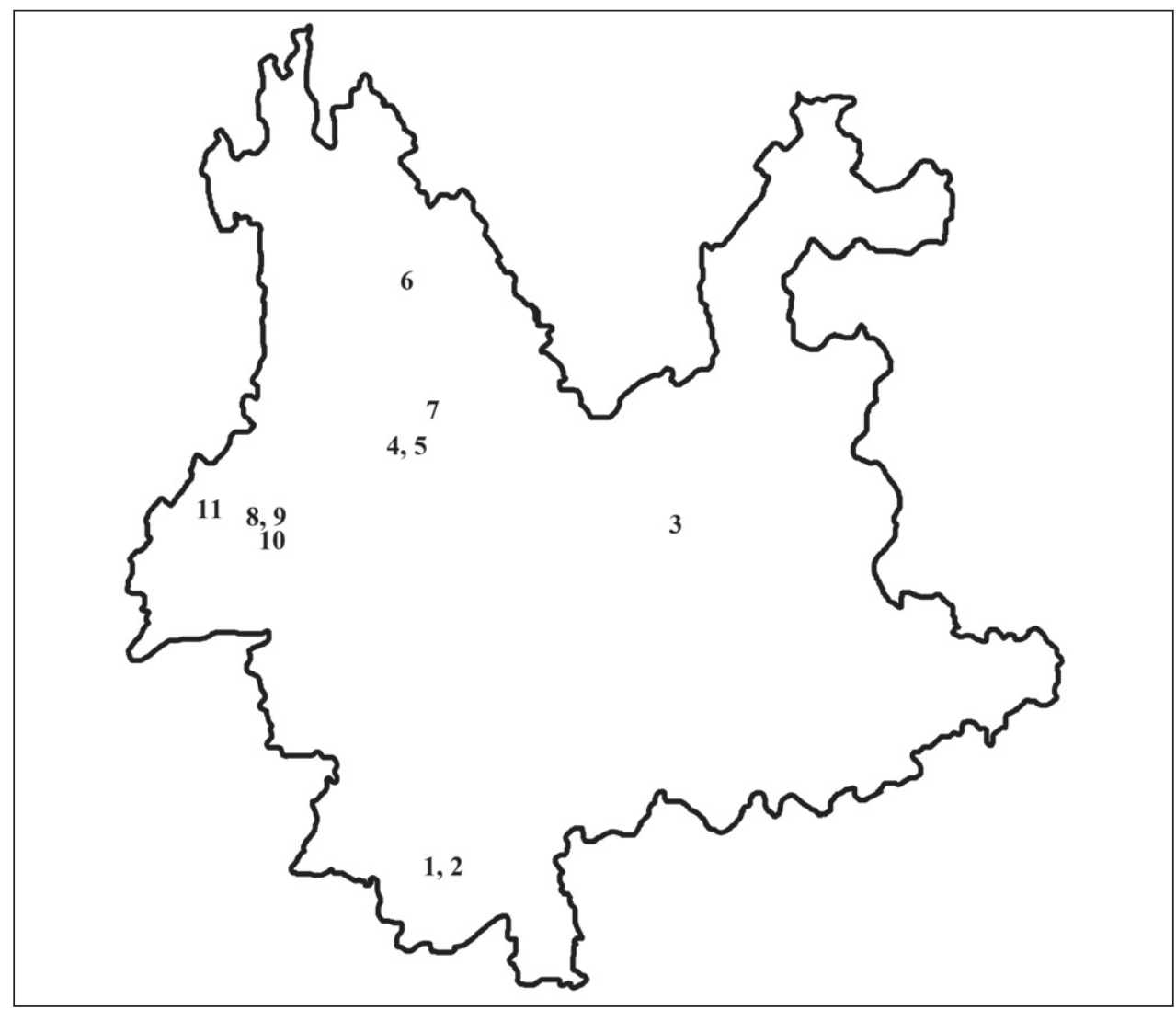

Figures 13. Map showing the collecting sites of the Nazeris in Yunnan Prov.; I N. nabanhensis sp. n. 2 N. caoi sp. n. 3 N. zhangi Watanabe \& Xiao 4 N. giganteus Watanabe \& Xiao 5 N. daliensis Watanabe \& Xiao 6 N. alpinus Watanabe \& Xiao 7 N. jizushanensis Watanabe \& Xiao 8 N. baibuaensis Watanabe \& Xiao 9 N. ishiianus Watanabe \& Xiao I0 N. nomurai Watanabe \& Xiao I I N. huanxipoensis Watanabe \& Xiao.

strong longitudinal median carina, which disappears behind anterior margin. Elytra slightly shorter than wide (length/width $=0.97)$, distinctly shorter $($ elytra/pronotum $=$ 0.80 ) and slightly narrower (elytra/pronotum $=0.97$ ) than pronotum.

Abdomen elongate, tergites without any microsculpture; densely and coarsely punctate. Seventh sternite (Fig. 8) distinctly emarginated in middle of posterior margin; 8th sternite (Fig. 9) with little short protrusion in middle, deeply excised in middle of posterior margin. Aedeagus (Figs 10, 11 and 12) well sclerotized; median lobe bi-lobed in dorsal view, curved ventrad in apical 1/3 in lateral view; dorso-lateral apophyses very thin, slightly curved ventrad, not extending to apices of median lobe.

Female. Seventh and 8th sternites simple. The other characters are similar to those of male.

Remarks. The present new species is similar in appearance to $N$. nabanhensis sp. $\mathrm{n}$. from the same locality, but can be distinguished from the latter by the following 
characters: postocular part more than twice as long as longitudinal diameter of each eye (in N. nabanhensis less than twice as long as longitudinal diameter of each eye); median lobe of aedeagus in dorsal view bi-lobed (in N. nabanhensis tri-lobed); dorso-lateral apophyses of aedeagus not extending to apices of median lobe (in $N$. nabanhensis extending beyond apices of median lobe). The new species can be distinguished from $N$. coomani Jarrige (1948: 40) from Vietnam by head with umbilicate punctation (in $N$. coomani punctation of head simple), and distinguished from $N$. odzisan Watanabe (1996: 1) from Vietnam by elytra shorter than wide (in $N$. odzisan elytra longer than wide); median lobe of aedeagus in dorsal view bi-lobed (in N. odzisan not lobed).

Etymology. The species is named in honor of Mr. Guanghong Cao of Nabanhe Nature Reserve, who helped us a lot during field work.

\section{Key to species of Nazeris from Yunnan Province, China}

1 Body length less than $4.5 \mathrm{~mm}$; posterior margin of male 7th sternite not emarginate ...................................................... N. zhangi Watanabe \& Xiao

- $\quad$ Body length at least $5.0 \mathrm{~mm}$; posterior margin of male 7th sternite emargin-

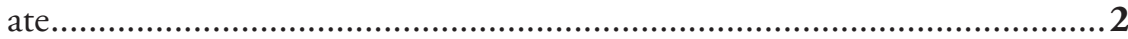

2 Male 8th sternite with short protrusion in middle, median lobe of aedeagus bi-lobed in dorsal view .............................................................. caoi sp. $\mathbf{n}$.

- $\quad$ Male 8th sternite without protrusion in middle, median lobe of aedeagus not

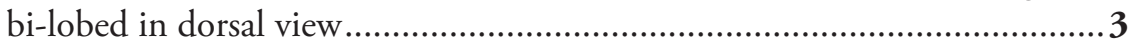
Median lobe of aedeagus tri-lobed in dorsal view N. nabanhensis sp. $\mathbf{n}$. Median lobe of aedeagus not tri-lobed in dorsal view..................................4 Dorso-lateral apophyses of aedeagus extending beyond apex of median lobe....5 Dorso-lateral apophyses of aedeagus not extending to apex of median lobe ....9 Dorso-lateral apophyses of aedeagus dilated in apical part and markedly curved ventrad in apical half.

N. nomurai Watanabe \& Xiao Dorso-lateral apophyses of aedeagus not dilated in apical part and not markedly curved ventrad in apical half.

6 Median lobe of aedeagus subtriangular in apical third and curved dorsad near apex in lateral view, dorso-lateral apophyses curved ventrad near apex in lateral view. N. huanxipoensis Watanabe \& Xiao Median lobe of aedeagus not subtriangular in posterior third, not curved dorsad near apex in lateral view, dorso-lateral apophyses nearly straight in lateral view

Dorso-lateral apophyses of aedeagus dilated at middle; median lobe of aedeagus without wing-shaped process $N$. baibuaensis Watanabe \& Xiao

- $\quad$ Dorso-lateral apophyses of aedeagus not dilated at middle; median lobe of aedeagus with a wing-shaped process on each side near middle..... Postocular part less than twice as long as eye length; depth of excision of posterior margin of male 8th sternite more than twice its width. 
- $\quad$ Postocular part more than twice as long as eye length; depth of excision of posterior margin of male 8 th sternite nearly the same its width

N. daliensis Watanabe \& Xiao

9 Median lobe of aedeagus semicircularly emarginate at apex.

$N$. ishiianus Watanabe $\&$ Xiao

- Median lobe of aedeagus not emarginate at apex.................................... 10

10 Median lobe of aedeagus tongue-shaped; dorso-lateral apophyses of aedeagus very narrow and near straight in dorsal view....N. alpinus Watanabe \& Xiao

- Median lobe of aedeagus not tongue-shaped, distinctly narrowed in apical $1 / 4$ in dorsal view; dorso-lateral apophyses of aedeagus markedly curved inward in dorsal view

N. giganteus Watanabe $\&$ Xiao

\section{Acknowledgements}

We thank Mr. Guanghong Cao and Mr. Maoxing Tian (Nabanhe Nature Reserve) for their help during field work. We thank Dr. Liang Tang and Mr. Ziwei Yin (Shanghai Normal University) for their collecting the specimens and continuous help in many ways. We thank Dr. Ales Smetana (Agriculture and Agri-Food Canada) for revision our paper. This study is supported by the National Natural Science Foundation of China (No. 30870323) and by Shanghai Normal University (No. SK200833 and SK200834).

\section{References}

Fauvel A (1873) Faune Gallo-Rhénane ou species des insectes qui habitent la France, la Belgique, la Hollande, le Luxembourg, la prusse Rhénane, la Nassau et la Valais avec tableaux synoptiques et planches gravées. Tome 3. Livraison 4. Caen: Le Blanc-Hardel, 215-390.

Jarrige J (1948) Staphylinides nouveaux d'Asie orientale. Notes d'Entomologie Chinoise, Musée Heude 12: 39-41.

Rougemont GM (1988) Un Nazeris nouveau de Thaïlande (Coleoptera, Staphylinidae, Paederinae). Revue Suisse de Zoologie 95: 773-777.

Watanabe Y (1996) A new Nazeris (Coleoptera, Staphylinidae) from northern Vietnam. Species Diversity 1: 1-5.

Watanabe Y, Xiao NN (1993) A new species of the genus Nazeris (Coleoptera, Staphylinidae) from Yunnan Province, Southwest China. Elytra, Tokyo 21(1): 129-133.

Watanabe Y, Xiao NN (1997) Four new Nazeris (Coleoptera, Staphylinidae) from Yunnan Province, Southwest China. Edaphologia (58): 1-12.

Watanabe Y, Xiao NN (2000) Four new species of the genus Nazeris (Coleoptera, Staphylinidae) from the Gaoligong Shan Mountains in Yunnan, Southwest China. Elytra, Tokyo 28(2): 311-321. 